\title{
RETRACTED ARTICLE: Positioning of UAV Base Stations Using 5G and Beyond Networks for loMT Applications
}

\author{
Taher M. Ghazal ${ }^{1,2}$
}

Received: 22 April 2021 / Accepted: 11 July 2021 / Published online: 4 August 2021

(c) King Fahd University of Petroleum \& Minerals 2021

The Editor-in-Chief and the publisher have retracted this article. The article was submitted to be part of a guest-edited issue. An investigation by the publisher found a number of articles, including this one, with a number of concerns, including but not limited to compromised editorial handling and peer review process, inappropriate or irrelevant references or not being in scope of the journal or guest-edited issue. Based on the investigation's findings the Editor-inChief therefore no longer has confidence in the results and conclusions of this article.
The author has not responded to correspondence regarding this retraction.

Supplementary Information The online version of this article (doi:https://doi.org/10.1007/s13369-021-05985-x) contains supplementary material, which is available to authorized users.

Springer Nature or its licensor holds exclusive rights to this article under a publishing agreement with the author(s) or other rightsholder(s); author self-archiving of the accepted manuscript version of this article is solely governed by the terms of such publishing agreement and applicable law.
Taher M. Ghazal

ghazal1000@ hotmail.com

1 Skyline University College, Sharjah, UAE

2 Universiti Kebangsaan Malaysia (UKM), Bangi, Malaysia 